Check for updates

Cite this: J. Mater. Chem. A, 2021, 9, 4291

Received 30th September 2020 Accepted 17th January 2021

DOI: 10.1039/d0ta09613j

rsc.li/materials-a

\section{Photocatalytic syngas production using conjugated organic polymers $\uparrow$}

\author{
Zhiwei Fu, (D) a Anastasia Vogel, (ID) a Martijn A. Zwijnenburg, (D ${ }^{\text {b }}$ Andrew I. Cooper (D) *a \\ and Reiner Sebastian Sprick (D) *ac
}

\begin{abstract}
A range of linear conjugated polymers is reported that promote photocatalytic $\mathrm{CO}_{2}$ reduction in water with a sacrificial hole-scavenger. Two photocatalysts containing dibenzo[b,d]thiophene sulfone were found to be the most active materials. A dibenzo[b,d]thiophene sulfone co-polymer with phenylene (P7) had the highest rate for producing $\mathrm{CO}$, but also for the co-evolution of $\mathrm{H}_{2}$. The homopolymer of dibenzo[b,d] thiophene sulfone was found to be less active for $\mathrm{CO}$ production, but had a higher $\mathrm{H}_{2}$ production rate, which is explained by changes in the driving-force favouring proton reduction. The co-evolution of hydrogen is facilitated by residual palladium from the material synthesis. By varying the amount of palladium in the photocatalyst, syngas can be obtained with varying ratios of $\mathrm{H}_{2}$ to $\mathrm{CO}$.
\end{abstract}

\section{Introduction}

The combustion of fossil fuels has resulted in increased concentrations of $\mathrm{CO}_{2}$ in the atmosphere, which in turn has caused more extreme weather events due to climate change. ${ }^{1}$ Much research is focused on replacing fossil fuels with 'green' solar derived alternative fuels, but it may ultimately be necessary to remove $\mathrm{CO}_{2}$ from the atmosphere to limit global warming. ${ }^{2}$ Carbon-capture and sequestration (CCS) is widely considered for this, but an alternative is to convert $\mathrm{CO}_{2}$, an unwanted side-product, into valuable chemicals through intermediates such as $\mathrm{CO}^{3}$ For example, mixtures of hydrogen and $\mathrm{CO}$ (syngas) are used in large-scale industrial processes such as the Fischer-Tropsch process. ${ }^{4}$

The electroreduction of $\mathrm{CO}_{2}$ into syngas has been studied widely, but this requires an additional bias to drive the reduction. ${ }^{4,5}$ Alternatively, photocatalytic $\mathrm{CO}_{2}$ reduction using sunlight and semiconductors as catalysts has been studied for the direct conversion of $\mathrm{CO}_{2}$ into value-added products. ${ }^{6}$ Most photocatalysts so far are either inorganic materials or molecular metal-organic compounds. Recently, there has been growing interest in using conjugated materials as photocatalysts due to

${ }^{a}$ Department of Chemistry and Materials Innovation Factory, University of Liverpool, 51 Oxford Street, Liverpool L7 3NY, UK. E-mail: aicooper@liverpool.ac.uk

${ }^{b}$ Department of Chemistry, University College London, 20 Gordon Street, London WC1H OAJ, UK

'Department of Pure and Applied Chemistry, University of Strathclyde, Thomas Graham Building, 295 Cathedral Street, Glasgow G1 1XL, UK. E-mail: sebastian. sprick@strath.ac.uk

$\dagger$ Electronic supplementary information (ESI) available: Experimental details, gas production data, UV/Vis, FT-IR and PL spectra, SEM, TEM images, TCSPC data and DFT results for P74 and TEA oxidation potentials. See DOI: 10.1039/d0ta09613j their tunability and large synthetic diversity, initially for photocatalytic hydrogen production, ${ }^{7-13}$ but more recently also for $\mathrm{CO}_{2}$ reduction. Organic materials such as conjugated microporous polymers (CMPs), ${ }^{14,15}$ covalent triazine-based frameworks (CTFs) ${ }^{16,17}$ covalent organic frameworks $(\mathrm{COFs})^{18-21}$ and unbranched conjugated polymers ${ }^{22}$ have been investigated for their potential as photocatalysts in $\mathrm{CO}_{2}$ reduction.

One of the challenges when using photocatalysts for syngas production is that different syngas compositions are required depending on its further processing, which could require either CO-rich or $\mathrm{H}_{2}$-rich mixtures ${ }^{4,23-25}$ This possess a challenge because the $\mathrm{H}_{2} / \mathrm{CO}$ ratios are difficult to control; hence, much research is focused on obtaining photocatalysts with high selectivity for $\mathrm{CO}$ over $\mathrm{H}_{2}$, with the $\mathrm{H}_{2}$ originating from a second, different process that is optimised for proton reduction.

\section{Results and discussion}

We started to explore if the co-evolution of both $\mathrm{H}_{2}$ and $\mathrm{CO}$ would be possible from a single material and whether the $\mathrm{H}_{2}$ : CO ratio could be controlled. For this, we prepared conjugated polymers via Suzuki-Miyaura polycondensation using $\operatorname{Pd}(0)$, which results in the formation of palladium particles within the material. This residual palladium has been shown previously to act as a co-catalyst for hydrogen production from water. ${ }^{26-28}$ Here, we study a range of photocatalysts: $p$-sexiphenylene, ${ }^{29}$ poly( $p$-phenylene) (P1), ${ }^{30}$ a carbazole-phenylene co-polymer (P4), ${ }^{30}$ a dibenzo[ $[b, d]$ thiophene sulfone co-polymer $(\mathrm{P} 7),{ }^{30,31}$ the homopolymer of dibenzo[b,d]thiophene sulfone (P10), ${ }^{31}$ a pyrimidine-phenylene co-polymer (P29), ${ }^{32}$ a bipyridine-phenylene co-polymer (P30), ${ }^{32}$ poly(pyridine) (P31), ${ }^{32}$ and poly(benzothiadiazole) (P74). 
All polymers were tested as photocatalysts for photocatalytic $\mathrm{CO}_{2}$ reduction under solar irradiation using a previously reported high-throughput work-flow. ${ }^{33,34}$ For this, vials were charged with photocatalysts $(5 \mathrm{mg}), \mathrm{CoCl}_{2}(1 \mu \mathrm{mol})$, which acts as the co-catalyst, and 2,2'-bipyridine (BPy, $2 \mathrm{mg}$ ), which is required to form catalytically active Co centres. ${ }^{22,35-38}$

These vials were then transferred to a liquid handling robot, and inertised under $\mathrm{CO}_{2}$. The liquid handler then added water $(1 \mathrm{~mL})$, acetonitrile (MeCN, $3 \mathrm{~mL})$, acting as an inert co-solvent, and triethanolamine (TEOA, $1 \mathrm{~mL}$ ), which acts as the hole scavenger before capping the vials. After this, the samples were sonicated to disperse the photocatalysts and transferred to a solar simulator (AM1.5G, $1600 \mathrm{~W}$ xenon light source, air mass 1.5G filter, 350-1000 nm). The samples were irradiated with constant agitation for a specific time before measurement of the gaseous products using an automated gas chromatograph.

It was found that $p$-sexiphenylene, P31 and P74 showed little or no activity under the conditions used for either CO or $\mathrm{H}_{2}$ production (Fig. 1c). Photocatalysts P1, P4, P29, and P30 all produced CO with rates between $68.8 \mu \mathrm{mol} \mathrm{g}^{-1} \mathrm{~h}^{-1}$ for P30 and $291.9 \mu \mathrm{mol} \mathrm{g}^{-1} \mathrm{~h}^{-1}$ for P4 and selectivities between $37 \%$ for P30 and $59 \%$ for $\mathrm{P} 4$ because significant amounts of $\mathrm{H}_{2}$ were produced. Both $\mathrm{P} 7$ and $\mathrm{P} 10$ showed significantly higher rates of CO production: $959.1 \mu \mathrm{mol} \mathrm{g}{ }^{-1} \mathrm{~h}^{-1}$ and $839.7 \mu \mathrm{mol} \mathrm{g}{ }^{-1} \mathrm{~h}^{-1}$. The high $\mathrm{CO}$ production rates of $\mathrm{P} 7$ and $\mathrm{P} 10$ are accompanied by a high $\mathrm{H}_{2}$ evolution rate of $1523.7 \mu \mathrm{mol} \mathrm{g}{ }^{-1} \mathrm{~h}^{-1}$ for P7 and an even higher $\mathrm{H}_{2}$ evolution rate of $2676.3 \mu \mathrm{mol} \mathrm{g}{ }^{-1} \mathrm{~h}^{-1}$ for P10, which is in line with the observation that P10 is a better hydrogen evolution photocatalyst than $\mathrm{P} 7 .{ }^{31}$ The high hydrogen evolution rates seem not to originate from oxidative dehydrogenation of TEOA as a side reaction, ${ }^{36}$ but may be explained by the presence of residual palladium, which acts as an efficient co-catalyst for proton reduction ${ }^{27,28}$ competing with cobalt sites for electrons. Together with the sluggish kinetics of $\mathrm{CO}_{2}$ reduction this results in poor $\mathrm{CO}$ production selectivity compared with other materials. No other products, such as methane, methanol, acetaldehyde or formate, were observed by gas chromatography and ion chromatography.
The role of palladium in the proton reduction reaction is further supported when looking at poly( $p$-phenylene) made via nickel catalysed Kumada-polycondensation (P1K) that contain residual nickel, which is a poorer hydrogen evolution cocatalyst. Hence, $\mathrm{P} 1 \mathrm{~K}$ has a higher $\mathrm{CO}$ evolution rate compared to P1 made via Suzuki-Miyaura polycondensation (189.7 vs. 77.7 $\left.\mu \mathrm{mol} \mathrm{g}^{-1} \mathrm{~h}^{-1}\right)$, and a higher selectivity for CO production (86\% vs. 37\%). Similarly, P10 made via Yamamoto coupling (P10Y) has a higher selectivity for $\mathrm{CO}$ over $\mathrm{H}_{2}$ compared to the SuzukiMiyaura polycondensation product (35\% vs. 24\%).

These observations show that palladium is, in general, a negative influence on $\mathrm{CO} / \mathrm{H}_{2}$ selectivity. In keeping with this, literature reports of materials with good selectivities are usually made using metal-free conditions, hence, resulting in materials that have no residual metal present that facilitate hydrogen production. ${ }^{20}$ However, we note that some systems that were produced using Pd-catalysed cross-coupling reactions have been reported by other researchers to produce $\mathrm{CO}$ with good selectivity over $\mathrm{H}_{2}$ despite their Pd-content. ${ }^{16}$

The particularly poor CO selectivity for P10 compared to the structurally similar P7 can be explained by the fact that the EA (electron affinity; that is, the LUMO) of P10 is less negative than for P7 (ref. 31) (Fig. 1b) and that hence P10 thus has a reduced thermodynamic driving force for reduction relative to $\mathrm{P} 7$. As $\mathrm{CO}_{2}$ reduction is thermodynamically slightly less favoured than reduction of protons $\mathrm{E}\left(\mathrm{CO}_{2}, \mathrm{H}^{+} / \mathrm{CO}\right)-0.63 \mathrm{~V}$ (ref. 40) $\mathrm{E}\left(\mathrm{H}^{+} / \mathrm{H}_{2}\right)$ $-0.52 \mathrm{~V} v s$. the standard hydrogen electrode, SHE, at $\mathrm{pH} 8.3$, which is the experimentally measured $\mathrm{pH}$ of the reaction mixture saturated with $\mathrm{CO}_{2}$, this reduction in driving force has a more significant impact on $\mathrm{CO}_{2}$ reduction.

Zooming out from the question of what drives $\mathrm{CO} / \mathrm{H}_{2}$ selectivity to what controls the overall activity of the different materials, we know from previous work on hydrogen evolution photocatalysts that the hydrogen evolution activity is often a trade-off between the polymers' optical properties (optical gap, the onset of light absorption), electronic properties (besides EA also IP, the ionisation potential, which controls the driving force for the oxidation of TEOA), and the dispersibility (a)

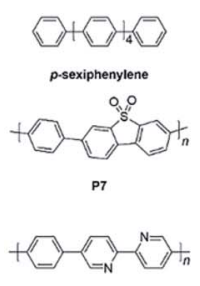

$\mathrm{P} 30$

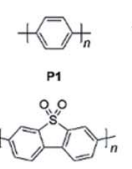

P10

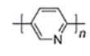

(b)

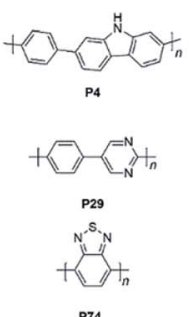

P74

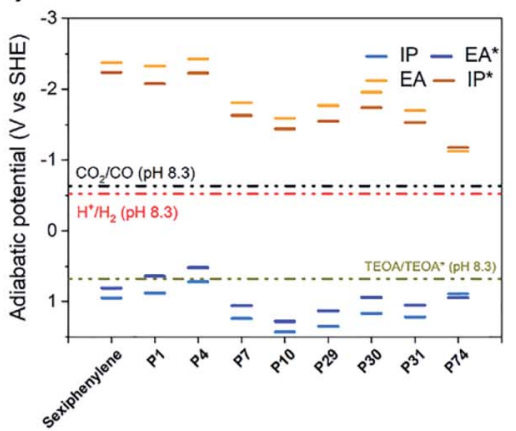

(c)

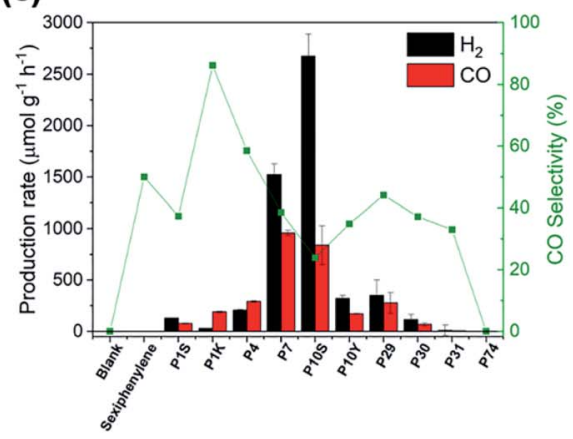

Fig. 1 (a) Structures of the photocatalysts; (b) predicted redox potentials of the polymer photocatalysts taken from the literature (P1-P31) ${ }^{30-32,39}$ or calculated in this study (P74, see ESI $\dagger$ ) and solution potentials $\left(\mathrm{CO}_{2}\right.$ and proton reduction, TEOA oxidation, see ESI $\dagger$ ) at pH 8.3 (the pH of the reaction mixture saturated with $\mathrm{CO}_{2}$ ) (c) evolution rates and selectivity of gaseous products produced by all photocatalysts in a high-throughput screening. Conditions: polymers ( $5 \mathrm{mg}), \mathrm{CoCl}_{2}(1 \mu \mathrm{mol}), 2,2^{\prime}$ - biyridine $(2 \mathrm{mg})$ solvent $\left(4 \mathrm{~mL}, \mathrm{MeCN} / \mathrm{H}_{2} \mathrm{O}=3: 1\right), \mathrm{TEOA}(1 \mathrm{~mL})$, solar simulator $(5$ hours), $\mathrm{CO}_{2}$ atmosphere. 
of the catalyst in the reaction medium. The oligomers and polymers with low activity are typically limited by one or more of these properties. $p$-Sexiphenylene and P1 adsorb limited visible light because they have the most blue-shifted optical gaps (see Fig. S5 $\dagger$ ). $p$-Sexiphenylene, $\mathrm{P} 1$ and $\mathrm{P} 4$ have the least positive IP values and thus the smallest driving force for the one-hole oxidation of TEOA (see Fig. 1B). P74 has the least negative EA value and thus the smallest driving force for proton or $\mathrm{CO}_{2}$ reduction. P29, P31 and especially P74, disperse very poorly in the reaction mixture. The most active materials, $\mathrm{P} 7$ and $\mathrm{P} 10$, in contrast are some of the most dispersible materials and are among the materials with the most positive IP values and, hence, the largest driving force for TEOA oxidation, while also having a significant driving force for proton and $\mathrm{CO}_{2}$ reduction. Also, especially for P10, these two polymers absorb a significant part of the visible spectrum.

We next went on to explore the performance of P7 $(5 \mathrm{mg})$ with different amounts of $\mathrm{CoCl}_{2}$ and BPy in a high-throughput screening experiment. It was found that an increased amount of $\mathrm{CoCl}_{2}$, while keeping its ratio with BPy constant, decreases the amounts of both $\mathrm{H}_{2}$ and $\mathrm{CO}$ produced (Fig. S-2 and Table S-2 $\dagger$ ), particularly when $5 \mu \mathrm{mol}$ or $10 \mu \mathrm{mol} \mathrm{CoCl}_{2}$ were used and the selectivity for $\mathrm{CO}$ was highest with $1 \mu \mathrm{mol} \mathrm{CoCl}_{2}$ and $2 \mathrm{mg}$ Bpy. Similar results were found when increasing the amount of $\mathrm{CoCl}_{2}$ while keeping the amount of BPy constant (Fig. S-2 and Table S-3†), while control experiments showed that $\mathrm{CoCl}_{2}$ and Bpy on their own in the absence of photocatalyst produce only negligible amounts of $\mathrm{H}_{2}$ and $\mathrm{CO}$, showing that the process is indeed photocatalytic and driven by the polymer photocatalyst (Table S-4†). Without BPy or $\mathrm{CoCl}_{2}$, we find that $\mathrm{CO}$ production rates are very low (Fig. S-17†), which is consistent with other reports that show that both are required to form catalytically active Co centres. ${ }^{2,35-38}$ We used $1 \mu \mathrm{mol} \mathrm{CoCl}_{2}$ and $2 \mathrm{mg}$ Bpy hereafter as the optimised conditions for photocatalytic $\mathrm{CO}_{2}$ reduction with $\mathrm{P} 7$. Residual palladium from the synthesis seems to facilitate competing hydrogen production. We therefore explored if controlling the concentration of residual palladium offers a pathway to producing syngas, hence mixtures of hydrogen and CO, in different ratios. For this, we simply varied the amount of $\left[\mathrm{Pd}\left(\mathrm{PPh}_{3}\right)_{4}\right]$ used in the synthesis of P7 from $0.1 \mathrm{~mol} \%$ to $5 \mathrm{~mol} \%$, which gave materials with varying amounts of residual palladium, ranging from $0.043 \mathrm{wt} \%$ up to $1.444 \mathrm{wt} \%$ as determined by inductively coupled plasma optical emission spectrometry (ICP-OES) measurements. While the amounts of residual palladium do not match the amounts used in the polycondensation reaction, we found that materials that were made using more palladium also contained more residual palladium, with an almost linear increase of residual palladium content of the polymer with increased amount of palladium catalyst used in the polymerisation (Fig. S-3†). These samples, denoted $\mathrm{P} 7-0.1 \%$ to $\mathrm{P} 7-5 \%$ indicating the amount of $\left[\mathrm{Pd}\left(\mathrm{PPh}_{3}\right)_{4}\right]$ used in the synthesis of each P7 sample, were then characterised to rule out that any other differences in properties beyond the palladium content that could affect the performance of these materials. UV-Vis absorption spectra measured in solidstate showed that the optical properties were not affected by the amount of palladium used in the polycondensation reaction with very little difference in their absorption on-sets (Fig. S- $4 \dagger$ ). Similarly, photoluminescence spectra show no difference in the maximum emission wavelength position (Fig. S-7†) and FT-IR spectra show no noticeable differences (Fig. S-8†). Secondary electron microscopy shows that all materials consist of irregular shaped micrometre sized particles in all cases (Fig. S-10†) and transmission electron microscopy (Fig. S-11†) show the presence of large Pd clusters in the case of $\mathrm{P} 7-1 \%$ and $\mathrm{P} 7-5 \%$ with the latter clearly showing a larger number of Pd clusters. A previous X-ray absorption spectroscopy study of the residual Pd in P10 has shown though that only the largest Pd clusters could be resolved and most Pd resides as very small clusters within the photocatalyst, which might also be the case here. ${ }^{\mathbf{4 1}}$

Taken together, all characterisation for the materials made using different amounts of catalyst in the synthesis (in the range of 0.1-5.0 mol\%) indicates little difference in their physical properties, except for their palladium content. We therefore went on to test $\mathrm{P} 7-0.1 \%$ to $\mathrm{P} 7-5 \%$ as photocatalysts for $\mathrm{CO}_{2}$ reduction under solar irradiation (Fig. 2a). The effect of the amount of residual Pd on the CO production rates for $\mathrm{P} 7-0.1 \%$ and $\mathrm{P} 7-0.5 \%$ was found to be insignificant with rates of 680.1 $\mu \mathrm{mol} \mathrm{g}{ }^{-1} \mathrm{~h}^{-1}$ and $660.4 \mu \mathrm{mol} \mathrm{g}{ }^{-1} \mathrm{~h}^{-1}$. P7-1\% and $\mathrm{P} 7-2 \%$ show a slight reduction in CO evolution rates $\left(567.4 \mu \mathrm{mol} \mathrm{g}^{-1} \mathrm{~h}^{-1}\right.$ and $539.8 \mu \mathrm{mol} \mathrm{g}{ }^{-1} \mathrm{~h}^{-1}$ ), and $\mathrm{P} 7-3 \%$ and $\mathrm{P} 7-5 \%$ show a significant reduction in their $\mathrm{CO}$ evolution rates $\left(465.8 \mu \mathrm{mol} \mathrm{g}^{-1} \mathrm{~h}^{-1}\right.$ and $\left.340.1 \mu \mathrm{mol} \mathrm{g}{ }^{-1} \mathrm{~h}^{-1}\right)$. By contrast, it was found that the hydrogen evolution rates are much more affected by the palladium content with an increase of the $\mathrm{H}_{2}$ evolution rate increasing from $275.0 \mu \mathrm{mol} \mathrm{g}^{-1} \mathrm{~h}^{-1}$ for P7-0.1\% to $711.9 \mu \mathrm{mol} \mathrm{g}{ }^{-1} \mathrm{~h}^{-1}$ for $\mathrm{P} 7-1 \%$ and $845.9 \mu \mathrm{mol} \mathrm{g}^{-1} \mathrm{~h}^{-1}$ for P7-2\%. Going to $\mathrm{P} 7-3 \%$ and $\mathrm{P} 7-5 \%$ a significant increase in the rate was again observed $\left(1130.2 \mu \mathrm{mol} \mathrm{g}{ }^{-1} \mathrm{~h}^{-1}\right.$ and $\left.1677.3 \mu \mathrm{mol} \mathrm{g}{ }^{-1} \mathrm{~h}^{-1}\right)$. This shows that the palladium concentration profoundly effects the activity of these photocatalysts for hydrogen production and can also be observed in a reduction of the photoluminescence intensity with increased palladium content (Fig. S-9†), possibly due to enhanced trapping and quenching of excitions. ${ }^{41}$ The residual Pd also effects the ability to reduce carbon dioxide, in particular at higher palladium concentrations. The observation that the hydrogen evolution rate in the limit of low Pd concentrations $(<0.2 \mathrm{wt} \%$, Fig. 2b) significantly increases with the amount of Pd is a common observation ${ }^{27,28}$ and shows that excitons or polarons after dissociation of excitons do not reach Pd to facilitate proton reduction, ${ }^{\mathbf{4 1}}$ while abundant Co is present allowing for efficient carbon dioxide reduction. The initial steep increase in activity is followed by a region that is less effected by the increase in palladium, which has also been observed for other conjugated materials ${ }^{27,28}$ before significantly increased $\mathrm{H}_{2}$ evolution rate, as more palladium relative to the amount of cobalt loaded on the materials is available for proton reduction. The ratios of $\mathrm{H}_{2} / \mathrm{CO}$ for $\mathrm{P} 7-0.1 \%$ to $\mathrm{P} 7-1 \%$ range from $0.4: 1$ to $1.25: 1 . \mathrm{H}_{2}$ rich syngas ranging from $1.6: 1$ to $4.9: 1\left(\mathrm{H}_{2} / \mathrm{CO}\right)$ were produced by $\mathrm{P} 7-2 \%$ to $\mathrm{P} 7-5 \%$. This makes it possible to produce syngas for the generation of aldehydes via hydroformylation of alkene with a ratio of $1: 1 \mathrm{H}_{2} / \mathrm{CO}$ as well as the methanol synthesis and $\mathrm{F}-\mathrm{T}$ synthesis of alkanes requiring a ratio of $2: 1 \mathrm{H}_{2} / \mathrm{CO} .{ }^{4}$ The lifetime of the excited states of $\mathrm{P} 1$ and 
(a)

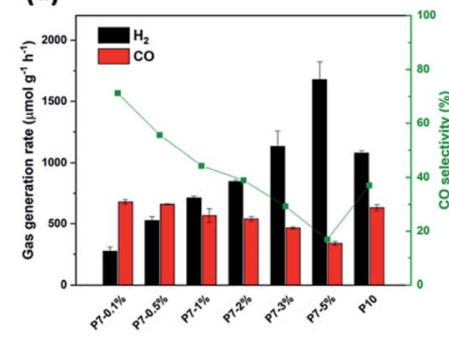

(b)

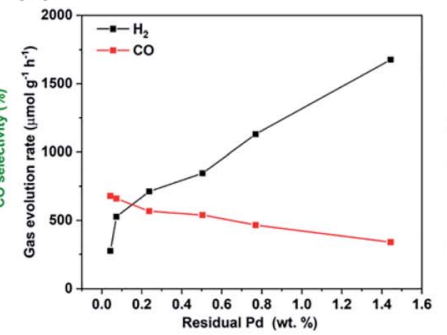

(c)

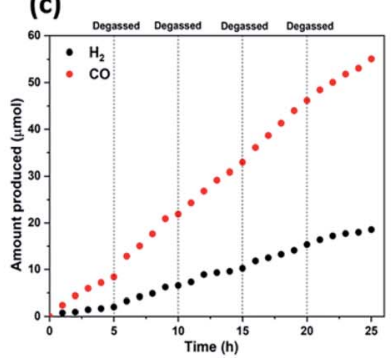

(d)

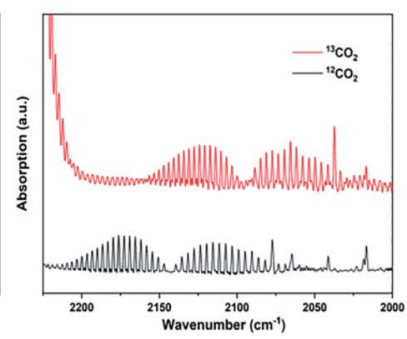

Fig. 2 (a) Photocatalytic $\mathrm{CO}$ and $\mathrm{H}_{2}$ production of P7-0.1\% to P7-5\% (5 mg) from MeCN/water/TEOA mixtures (25 mL, 3/1/1) under simulated solar irradiation (1 sun, AM 1.5G); (b) correlation between the amount of palladium and the CO and hydrogen evolution rates of P7-0.1\% to P7-5\%; (c) cycling experiments of P7-0.1\% (5 mg) under simulated solar irradiation (1 sun, AM 1.5G) over 25 hours irradiation with intermitted degassing every 5 hours; (d) FT-IR spectra of the gaseous products after 1 hour of $\mathrm{P} 7 \mathrm{in} \mathrm{MeCN} / \mathrm{H}_{2} \mathrm{O} / \mathrm{TEOA}$ solution using either ${ }^{12} \mathrm{CO}_{2}$ and ${ }^{13} \mathrm{CO}_{2}$ under solar irradiation (1 sun, AM 1.5G).

P7 were studied by time-correlated single photon counting (TCSPC) experiments. The average weighted photoluminescence emission lifetime (Table S-6 $\dagger)$ of P7 ( $\tau_{\text {avg }}=1.13$ $\left.\mathrm{ns}, \lambda_{\mathrm{em}}=475 \mathrm{~nm}\right)$ was similar with that $\left(\tau_{\mathrm{avg}}=1.05 \mathrm{~ns}, \lambda_{\mathrm{em}}=\right.$ $475 \mathrm{~nm}$ ) in MeCN purged with $\mathrm{CO}_{2}$. When measured in MeCN/ $\mathrm{H}_{2} \mathrm{O}$ /TEOA suspension, the average emission lifetime of $\mathrm{P} 7$ ( $\tau_{\text {avg }}$ $\left.=0.80 \mathrm{~ns}, \lambda_{\mathrm{em}}=475 \mathrm{~nm}\right)$ was longer than that of P1 $\left(\tau_{\mathrm{avg}}=0.5\right.$ $\mathrm{ns}, \lambda_{\mathrm{em}}=453 \mathrm{~nm}$ ), in line with the observed activity.

Longer-term experiments with intermittent degassing every 5 hours showed good stability of the sample (P7-0.1\%) over 25 hours producing $\mathrm{CO}$ rich syngas (Fig. 2c). Using isotopically labelled ${ }^{13} \mathrm{CO}_{2}$ as the carbon source resulted in the formation of ${ }^{13} \mathrm{CO}$ strongly suggesting that $\mathrm{CO}_{2}$ was the source of the produced $\mathrm{CO}$ (Fig. 2d). Furthermore, the action spectrum of P7-0.1\% follows broadly speaking the light absorption profile also supporting the hypothesis that the $\mathrm{CO}$ production is indeed photocatalytic.

\section{Conclusions}

In conclusion, we show that linear conjugated polymers can be used as photocatalysts for $\mathrm{CO}_{2}$ reduction to $\mathrm{CO}$ in the presence of a sacrificial hole scavenger. Polymer P7 was found to be the most active photocatalyst for $\mathrm{CO}_{2}$ reduction, while the structurally related P10 performs far worse in terms of CO selectivity, producing a similar amount of $\mathrm{CO}$ but much more hydrogen. This difference in selectivity can be rationalised by differences in the predicted thermodynamic driving force for $\mathrm{CO}_{2}$ and proton reduction for $\mathrm{P} 7$ and P10. Residual palladium was found to result in significant hydrogen production, which was found to compete with $\mathrm{CO}$ production at high loadings. Within a certain concentration range, Pd acts as a co-catalyst for $\mathrm{H}_{2}$ production without reducing the $\mathrm{CO}$ evolution rates significantly, potentially allowing for syngas production, if the production efficiencies can be increased, within a range of $\mathrm{H}_{2} /$ $\mathrm{CO}$ ratios that are adjustable by varying the Pd concentration.

\section{Experimental section}

\section{General methods}

All reagents were obtained from Sigma-Aldrich, TCI, ABCR, Fisher Scientific or Fluorochem and used as received. Cobalt(II) chloride hexahydrate (BioReagent), 2,2'-bipyridyl (Reagent Plus, $\geq 99 \%)$ and triethanolamine ( $\geq 99.0 \%)$ were purchased from Sigma-Aldrich. Acetonitrile (HPLC gradient grade), $N, N^{\prime}$-dimethylformamide (GC Headspace Grade) were obtained from Fisher Scientific. Water for the $\mathrm{CO}_{2}$ reduction experiments was purified using an ELGA LabWater system with a Purelab Option S filtration and ion exchange column $\left(\rho=15 \mathrm{M} \Omega \mathrm{cm}^{-1}\right)$ without $\mathrm{pH}$ level adjustment. Reactions were carried out under nitrogen atmosphere using standard Schlenk techniques. Photocatalysts $\mathrm{P} 1 \mathrm{~K},{ }^{30} \mathrm{P} 1 \mathrm{~S},{ }^{30} \mathrm{P} 4,{ }^{30} \mathrm{P} 7,{ }^{30} \mathrm{P} 10,{ }^{31} \mathrm{P} 29,{ }^{32} \mathrm{P} 30,{ }^{32}$ and $\mathrm{P} 31$ (ref. 32) were prepared according to literature procedures.

\section{Synthesis of P74}

4,7-Dibromo-2,1,3-benzothiadiazole ( $412 \mathrm{mg}, 1.4 \mathrm{mmol}$ ), 2,1,3benzothiadiazole-4,7-bis(boronic acid pinacol ester) $(543 \mathrm{mg}$, $1.4 \mathrm{~mL}$ ), $N, N$-dimethylformamide $\left(40 \mathrm{~mL}\right.$ ) and $\mathrm{K}_{2} \mathrm{O}_{3}$ (aqueous, $2 \mathrm{M}, 8 \mathrm{~mL}$ ) were combined and degassed with nitrogen for 30 minutes. Then $\left[\mathrm{Pd}\left(\mathrm{PPh}_{3}\right)_{4}\right](40 \mathrm{mg})$ was added and heated to $150{ }^{\circ} \mathrm{C}$ for 2 days. After cooling to room temperature, the reaction mixture was poured into water, the solids were filtered off and washed with methanol. The polymer was purified using a Soxhlet extraction with chloroform to give P74 as a dark powder (387 mg, quant.). Anal. calcd for $\left(\mathrm{C}_{6} \mathrm{H}_{2} \mathrm{~N}_{2} \mathrm{~S}\right)_{n}$ : $\mathrm{C}, 53.72 ; \mathrm{H}$, $1.50 ; \mathrm{N}, 20.88 \%$; found $\mathrm{C}, 49.13 ; \mathrm{H}, 0.95 ; \mathrm{N}, 18.26 \%$

\section{High-throughput $\mathrm{CO}_{2}$ reduction experiments}

Polymer $(5 \mathrm{mg}), \mathrm{CoCl}_{2}(0.5-10 \mu \mathrm{mol})$ and 2,2'-bipyridine (1.0-20 $\mathrm{mg})$ were added into sample vials $(V=12.5 \mathrm{~mL})$ and purged with carbon dioxide in a Sweigher Chemspeed Technologies robotic platform for 3 hours. A liquid handling system transferred water/solvent/hole-scavenger mixture (water/acetonitrile/ triethanolamine, $1: 3: 1,5 \mathrm{~mL}$ ) from stock jars inside the system into the sample vials. A capper/crimper tool was then used to automatically seal the vials under $\mathrm{CO}_{2}$ atmosphere. All sample vials were ultrasonicated in an ultrasonic bath for 5 minutes before illumination using a solar simulator (AM1.5G, Class AAA, IEC/JIS/ASTM, $1440 \mathrm{~W}$ xenon, $12 \times 12$ in, MODEL:94123A) for the time specified while constantly being redispersed with a rocker/roller device. Samples of gaseous products were analysed using a Shimadzu 2014 HS-GC gas 
chromatograph equipped with a ShinCarbon ST micropacked column (Restek 80-100 mesh, $2 \mathrm{~m}$ length, $0.53 \mathrm{~mm}$ inner diameter) and a thermal conductivity detector. All samples were duplicated to ensure reproducibility within a run.

\section{$\mathrm{CO}_{2}$ Reduction experiments}

A quartz flask was charged with polymer powder (5 mg), 2,2'bipyridine $(10 \mathrm{mg})$, cobalt(II) chloride $(5 \mu \mathrm{mol})$, a mixture of acetonitrile, water and triethanolamine (3:1:1 vol, $25 \mathrm{~mL}$ ), and sealed with a septum. The resulting suspension was ultrasonicated for 20 minutes and then purged with $\mathrm{CO}_{2}$ for 30 minutes. The mixture was illuminated an Oriel Instruments LSH-7320 Solar Simulator (IEC ABA certified) with 1 Sun output. Laser adjustment of the instrument was used to adjust the distance of the reaction flask to the light source. Samples of gaseous products were taken with a gas-tight syringe and run on a Shimadzu GC-2014 gas chromatograph equipped with a ShinCarbon ST micropacked column (Restek 80-100 mesh, 2 $\mathrm{m}$ length, $0.53 \mathrm{~mm}$ inner diameter) and a thermal conductivity detector. Gases dissolved in the reaction mixture and the pressure increase generated by the evolved gases was neglected in the calculations.

\section{Determination of external quantum efficiency for CO production}

The external quantum efficiencies of $\mathrm{CO}$ production were determined using monochromatic LED light $(\lambda=395,405,420$, 490 and $515 \mathrm{~nm}$ ). The reactions were conducted on the same photochemical experimental setup under the optimised reaction conditions. For the experiments, P7-0.1\% (1 mg) 2,2'bipyridine $(2 \mathrm{mg})$ and cobalt(II) chloride $(1 \mu \mathrm{mol})$ were suspended in acetonitrile, water and triethanolamine $(3: 1: 1$ vol. mixture, $5 \mathrm{~mL}$ ). The illuminated area was $8 \mathrm{~cm}^{2}$ and the light intensity was measured by a ThorLabs PM100D Power and Energy Meter Console with a ThorLabs S120VC photodiode power sensor. The EQE was calculated using the following equation:

$$
\mathrm{EQE} \%=2 \times\left[(n \mathrm{CO}) \times N_{\mathrm{A}} \times h \times c\right] \times 100 \% /(I \times S \times t \times \lambda)
$$

where, $N_{\mathrm{A}}$ is Avogadro constant $\left(6.022 \times 10^{23} \mathrm{~mol}^{-1}\right), h$ is the Planck constant $\left(6.626 \times 10^{-34} \mathrm{~J} \mathrm{~s}\right), c$ is the speed of light $(3 \times$ $\left.10^{8} \mathrm{~m} \mathrm{~s}^{-1}\right), S$ is the irradiation area $\left(\mathrm{cm}^{2}\right), I$ is the intensity of irradiation light $\left(\mathrm{W} \mathrm{cm}^{-2}\right), t$ is the photoreaction time (s), $\lambda$ is the wavelength of the monochromatic light (m).

\section{Isotopic labelling experiments}

${ }^{13} \mathrm{CO}_{2}$ Labelling experiments were carried on a Bruker Vertex $70 \mathrm{~V}$ Fourier-transform infrared spectrometer with an argonpurged custom-made gas IR cell. A vial containing the photocatalyst, 2,2'-bipyridine and cobalt(II) chloride in a mixture of acetonitrile/water/triethanolamine $(3: 1: 1)$ was purged with ${ }^{13} \mathrm{CO}_{2}$ (Sigma-Aldrich, 99 atom\% ${ }^{13} \mathrm{C},<3$ atom\% ${ }^{18} \mathrm{O}$ ) for 3 minutes. Then the resulting suspension was illuminated for 1 hour using an Oriel Instruments LSH-7320 Solar Simulator (IEC ABA certified) with 1 Sun output. A sample of the gas headspace
$(1000 \mu \mathrm{L})$ was injected into the gas IR cell and the IR spectrum was measured ( 32 scans with a resolution of $0.5 \mathrm{~cm}^{-1}$ ). Background was measured using Ar purged cell and subtracted from the measurement.

\section{Conflicts of interest}

There are no conflicts to declare.

\section{Acknowledgements}

We thank the Engineering and Physical Sciences Research Council (EPSRC) for financial support under Grant EP/N004884/ 1. Z. Fu thanks the China Scholarship Council for a $\mathrm{PhD}$ studentship. A. V. thanks the European Union's Horizon 2020 research and innovation programme (Marie-Skłodowska-Curie Individual Fellowship) for financial support under grant agreement No. 796322. R. S. S. thanks the University of Strathclyde for financial support through The Strathclyde Chancellor's Fellowship Scheme. Dr G. Neri and Prof. A. Cowan are thanked for help with the FT-IR measurements. I. HeathApostolopoulos is acknowledged for help with the calculations. R. Clowes is thanked for help with high-throughput measurements. L. Liu is acknowledged for SEM measurements and Dr C. M. Aitchison TEM measurements.

\section{References}

1 T. M. L. Wigley, Science, 2005, 307, 1766-1769.

2 S. J. Davis, K. Caldeira and H. D. Matthews, Science, 2010, 329, 1330-1333.

3 S. Chu, Science, 2009, 325, 1599.

4 S. R. Foit, I. C. Vinke, L. G. J. de Haart and R. A. Eichel, Angew. Chem., Int. Ed., 2017, 56, 5402-5411.

5 W. Zhu, J. Fu, J. Liu, Y. Chen, X. Li, K. Huang, Y. Cai, Y. He, Y. Zhou, D. Su, J. J. Zhu and Y. Lin, Appl. Catal., B, 2020, 264, 118502.

6 K. Li, B. Peng and T. Peng, ACS Catal., 2016, 6, 7485-7527.

7 Y. Wang, A. Vogel, M. Sachs, R. S. Sprick, L. Wilbraham, S. J. A. Moniz, R. Godin, M. A. Zwijnenburg, J. R. Durrant, A. I. Cooper and J. Tang, Nat. Energy, 2019, 4, 746-760.

8 J. Jayakumar and H. H. Chou, ChemCatChem, 2020, 12, 689704.

9 Y. Miseki and K. Sayama, Adv. Energy Mater., 2019, 9, 1801294.

10 L. Y. Ting, J. Jayakumar, C. L. Chang, W. C. Lin, M. H. Elsayed and H. H. Chou, J. Mater. Chem. A, 2019, 7, 22924-22929.

11 C.-L. Chang, W.-C. Lin, C.-Y. Jia, L.-Y. Ting, J. Jayakumar, M. H. Elsayed, Y.-Q. Yang, Y.-H. Chan, W.-S. Wang, C.-Y. Lu, P.-Y. Chen and H.-H. Chou, Appl. Catal., B, 2020, 268, 118436.

12 A. F. M. EL-Mahdy, A. M. Elewa, S. W. Huang, H. H. Chou and S. W. Kuo, Adv. Opt. Mater., 2020, 8, 2000641.

13 W. H. Wang, L. Y. Ting, J. Jayakumar, C. L. Chang, W. C. Lin, C. C. Chung, M. H. Elsayed, C. Y. Lu, A. M. Elewa and H. H. Chou, Sustainable Energy Fuels, 2020, 4, 5264-5270. 
14 Y. Chen, G. Ji, S. Guo, B. Yu, Y. Zhao, Y. Wu, H. Zhang, Z. Liu, B. Han and Z. Liu, Green Chem., 2017, 19, 5777-5781.

15 H. P. Liang, A. Acharjya, D. A. Anito, S. Vogl, T. X. Wang, A. Thomas and B. H. Han, ACS Catal., 2019, 10, 3959-3968. 16 C. Yang, W. Huang, L. C. da Silva, K. A. I. Zhang and X. Wang, Chem.-Eur. J., 2018, 24, 17454-17458.

17 S. Zhang, S. Wang, L. Guo, H. Chen, B. Tan and S. Jin, J. Mater. Chem. C, 2019, 8, 192-200.

18 S. Yang, W. Hu, X. Zhang, P. He, B. Pattengale, C. Liu, M. Cendejas, I. Hermans, X. Zhang, J. Zhang and J. Huang, J. Am. Chem. Soc., 2018, 140, 14614-14618.

19 W. Zhong, R. Sa, L. Li, Y. He, L. Li, J. Bi, Z. Zhuang, Y. Yu and Z. Zou, J. Am. Chem. Soc., 2019, 141, 7615-7621.

20 Z. Fu, X. Wang, A. M. Gardner, X. Wang, S. Y. Chong, G. Neri, A. J. Cowan, L. Liu, X. Li, A. Vogel, R. Clowes, M. Bilton, L. Chen, R. S. Sprick and A. I. Cooper, Chem. Sci., 2020, 11, 543-550.

21 X. Wang, Z. Fu, L. Zheng, C. Zhao, X. Wang, S. Y. Chong, F. McBride, R. Raval, M. Bilton, L. Liu, X. Wu, L. Chen, R. S. Sprick and A. I. Cooper, Chem. Mater., 2020, 32, 91079114.

22 S. Wang, X. Hai, X. Ding, S. Jin, Y. Xiang, P. Wang, B. Jiang, F. Ichihara, M. Oshikiri, X. Meng, Y. Li, W. Matsuda, J. Ma, S. Seki, X. Wang, H. Huang, Y. Wada, H. Chen and J. Ye, Nat. Commun., 2020, 11, 1149.

23 B. Acharya, P. Roy and A. Dutta, Biofuels, 2014, 5, 551-564.

24 S. Hernández, M. A. Farkhondehfal, F. Sastre, M. Makkee, G. Saracco and N. Russo, Green Chem., 2017, 19, 2326-2346.

25 M. B. Ross, Y. Li, P. De Luna, D. Kim, E. H. Sargent and P. Yang, Joule, 2019, 3, 257-264.

26 L. Li, Z. Cai, Q. Wu, W. Y. Lo, N. Zhang, L. X. Chen and L. Yu, J. Am. Chem. Soc., 2016, 138, 7681-7686.

27 J. Kosco, M. Sachs, R. Godin, M. Kirkus, L. Francas, M. Bidwell, M. Qureshi, D. Anjum, J. R. Durrant and I. McCulloch, Adv. Energy Mater., 2018, 8, 1802181.

28 R. S. Sprick, Y. Bai, A. A. Y. Guilbert, M. Zbiri, C. M. Aitchison, L. Wilbraham, Y. Yan, D. J. Woods, M. A. Zwijnenburg and A. I. Cooper, Chem. Mater., 2019, 31, 305-313.
29 S. Yanagida and S. Matsuoka, in Optical Materials Technology for Energy Efficiency and Solar Energy Conversion XI: Photovoltaics, Photochemistry, Photoelectrochemistry, es. A. Hugot-Le Goff, C.-G. Granqvist and C. M. Lampert, 1992, vol. 1729, p. 243.

30 R. S. Sprick, B. Bonillo, R. Clowes, P. Guiglion, N. J. Brownbill, B. J. Slater, F. Blanc, M. A. Zwijnenburg, D. J. Adams and A. I. Cooper, Angew. Chem., Int. Ed., 2016, 55, 1792-1796.

31 M. Sachs, R. S. Sprick, D. Pearce, S. A. J. Hillman, A. Monti, A. A. Y. Guilbert, N. J. Brownbill, S. Dimitrov, X. Shi, F. Blanc, M. A. Zwijnenburg, J. Nelson, J. R. Durrant and A. I. Cooper, Nat. Commun., 2018, 9, 4968.

32 R. S. Sprick, L. Wilbraham, Y. Bai, P. Guiglion, A. Monti, R. Clowes, A. I. Cooper and M. A. Zwijnenburg, Chem. Mater., 2018, 30, 5733-5742.

33 C. B. Meier, R. Clowes, E. Berardo, K. E. Jelfs, M. A. Zwijnenburg, R. S. Sprick and A. I. Cooper, Chem. Mater., 2019, 31, 8830-8838.

34 Y. Bai, L. Wilbraham, B. J. Slater, M. A. Zwijnenburg, R. S. Sprick and A. I. Cooper, J. Am. Chem. Soc., 2019, 141, 9063-9071.

35 M. Zhou, S. Wang, P. Yang, C. Huang and X. Wang, ACS Catal., 2018, 8, 4928-4936.

36 J. Lin, Z. Pan and X. Wang, ACS Sustainable Chem. Eng., 2014, 2, 353-358.

37 S. Wang, B. Y. Guan, Y. Lu and X. W. Lou, J. Am. Chem. Soc., 2017, 139, 17305-17308.

38 J. J. Walsh, C. Jiang, J. Tang and A. J. Cowan, Phys. Chem. Chem. Phys., 2016, 18, 24825-24829.

39 P. Guiglion, C. Butchosa and M. A. Zwijnenburg, J. Mater. Chem. A, 2014, 2, 11996-12004.

40 S. G. Bratsch, J. Phys. Chem. Ref. Data, 1989, 18, 1-21.

41 M. Sachs, H. Cha, J. Kosco, C. M. Aitchison, L. Francàs, S. Corby, C. L. Chiang, A. A. Wilson, R. Godin, A. FaheyWilliams, A. I. Cooper, R. S. Sprick, I. McCulloch and J. R. Durrant, J. Am. Chem. Soc., 2020, 142, 14574-14587. 